\title{
Determination of heavy metals of road deposited sediment in Ado-Ekiti, Nigeria using XRF Technique
}

\author{
O. T. Ogunmodede ${ }^{1}$, O. O. Ajayi ${ }^{2}$ \\ ${ }^{1}$ Department of Chemical Science, Afe Babalola University, Ado-Ekiti, Ekiti State, Nigeria \\ ${ }^{2}$ Department of Industrial Chemistry, Federal University of Technology, Akure, Ondo State, Nigeria
}

\begin{abstract}
In this work x-ray fluorescence(XRF) technology was used to evaluate the soil pollution with heavy metals $(\mathrm{K}, \mathrm{Ti}, \mathrm{Cr}, \mathrm{Mn}, \mathrm{Fe}, \mathrm{Cu}, \mathrm{Zr})$ in rain run-off deposited metal sediment of road side soil in Ado Ekiti, Nigeria. The investigated sediment of road side was collected in open places along the road at different districts in Ado Ekiti. XRF was carried out at the laboratory of Obafemi Awolowo University centre for energy research using handheld thermo scientific energy-dispersive XRF analyzer. The experimental result indicate that the concentration of heavy elements in Adebayo road is the highest level detected while the road at new Iyin road is lowest and they are greater than the level detected in a control soil collected from a zone situated far from the road. For the majority of metals, pronounced maximum, concentrations were detected in the site. Anthropogenic releases give rise to highest concentrations of the metals relative to the normal background values and in some locations their levels exceed the alert level admitted by the Nigeria guideline.
\end{abstract}

Keywords: X -Ray fluorescence (XRF) technique; heavy metals; soil pollution; anthropogenic

\section{INTRODUCTION}

Sediments on road surfaces and in curbside areas are ubiquitous in urban and sub-urban drainage basins. These deposits are easily sampled, and provide a useful indicator of the degree of pollution status of a locate [1], curbside sediment and associated contaminants are typically available for mobilization and transportation to sub surface drainage system by storm water run-off. Established research has shown that sediments and dusts transported and stored in the urban environment have the potential to provide consider able loading of heavy metals to receiving water and water bodies particularly with charging environmental conditions [2]. Street sediments that accumulate along parameters in urban environments originate mainly from natural and anthropogenic sources. Heavy metal from natural sources vary significally within catchment and may include materials transported by water from surrounding soils, pollutants from dry and net atmospheric deposition and biological materials from vegetation. Significant quality of particulate matter can also be attributed to anthropogenic sources such as abrasion of vehicular component and their exhaust emission, incinerators, power plants and foundry operations, type and road surface wear [3,4]. These deposits as street sediments have become an important medium for study of anthropogenic pollutants and their possible sources [5-9]. Urban street sediment has limited residence tunes and therefore provides a record of recent accumulation $[10,11]$. The attractiveness of nondestructive method and the ability to perform simultaneous multi-elemental determination has to an extensive application in industrial and research laboratories of accurate, precise and sensitive atomic and unclear analytical techniques for the investigation of different types of 
materials. The main goal of the present research was to use XRF techniques in order to assess the heavy metals distribution in road side soil sediments in Ado- Ekiti Nigeria.

\section{MATERIALS AND METHODS}

Studied area was Ado Ekiti city which his at $70^{\circ} 31^{\prime} \mathrm{N}$ and $5^{\circ} 5^{\prime} \mathrm{E}$. Fifty sediment sample were collected from ten reads from five districts of the city with the aid of stainless spoon, washed with soap and rinsed with district water for each sampling [12]. These roads are Adebayo road, Basin road, Ilawe road, Ajilosun road, Mathew road, Okeyinmi road, New Iyin road, Odo-Ado road, State secretariat road, University road. Two sampling site were designated on each road. The samples were collected once every month for five month during the rainy reason from May to September 2012. All the samplings were perform three days after the rain. Sample collected were stored in sealed polythene bags and transported to the laboratory for pre- treatment and analyses. Soil sample were air dried, mechanically ground using a stainless shell roller and serve to Obtain $<2 \mathrm{~mm}$ fraction. A 20-30 g sub sample was drawn from the bulk soil ( $<2 \mathrm{~mm}$ fraction) and reground to obtain $<200 \mathrm{~mm}$ fraction using a mortar and pestle. The fire material used to determine the $\mathrm{pH}$ using soil water ratio of 1:5 using a consorte $\mathrm{C} 862$ bench top conductivity /pH/Do meter. Organic carbon was determine by the method walkley and Black method. XRF analyzes were carried out at the laboratory using hand held thermo scientific XLT;- 793 NITON energy- dispersive XRF analyzer having as excitation source a miniaturized $30 \mathrm{ku}$ X-ray tube. Each soil sample was analyzed five times for $240 \mathrm{~s}$ using two X-ray filters, one for elements from $\mathrm{k}$ to cu and the second for element from $\mathrm{Zu}$ to $\mathrm{Sb}$.

\section{RESULT AND DISCUSSION}

Soil $\mathrm{PH}$ value are presented in Table 1 medication that the soils collected around Adebayo, New Iyin road, Basiri road, Mathew road, Ajilosun, road, Ilawe road, Okeyinmi road, Odo-Ado road, state secretariat road, and University road are alkaline ( $\mathrm{pH}$ in the range of $7.973 \pm 0.05$ to $8.846 \pm 0.12)$ and the control soil of Ado- Ekiti city is slightly and ( $\mathrm{pH}=$ $6.185 \pm 0.05)$.

Table 1. Mean values PH for the investigated soil sample.

\begin{tabular}{|c|c|c|c|c|c|c|c|c|c|c|c|}
\hline $\begin{array}{c}\text { Soil } \\
\text { sample }\end{array}$ & 1 & 2 & 3 & 4 & 5 & 6 & 7 & 8 & 9 & 10 & control \\
\hline $\mathrm{pH}$ & 8.846 & 8.837 & 8.662 & 8.409 & 8.783 & 8.484 & 8.442 & 8.557 & 7.973 & 8.373 & 6.185 \\
\pm 0.12 & \pm 0.07 & \pm 0.14 & \pm 0.03 & \pm 0.05 & \pm 0.02 & \pm 0.06 & \pm 0.10 & \pm 0.05 & \pm 0.22 & \pm 0.07 \\
\hline
\end{tabular}

XRF result for the collected soil samples evidentiated the existence of the following major and minor element: $\mathrm{Fe}, \mathrm{K}, \mathrm{Mn}, \mathrm{Ti}$ (major) and $\mathrm{Cr}, \mathrm{Cu}, \mathrm{Ni}$, and $\mathrm{Zr}$ (minor). The average concentrations of heavy metal $\mathrm{Mn}, \mathrm{Cr}, \mathrm{Cu}, \mathrm{Ni}$, and, $\mathrm{Zr}$ of five measurement of each of the soil sample are given in Table 2. For the element, $\mathrm{Ag}, \mathrm{Cd}, \mathrm{Hg}$, Sb, Se, and $\mathrm{Sn}$ the XRF result have not been reported because their concentration were below the detection limits. 
Table 2. Mean values of heavy metal content in the investigated soils sample.

\begin{tabular}{|c|c|c|c|c|c|c|c|c|c|c|c|}
\hline Element & 1 & 2 & 3 & 4 & 5 & 6 & 7 & 8 & 9 & 10 & control \\
\hline $\mathrm{Fe}$ & 476.88 & 461.72 & 460.66 & 412.30 & 456.38 & 427.20 & 443.15 & 430.50 & 411.20 & 410.13 & 187.52 \\
\hline $\mathrm{K}$ & 58.40 & 55.33 & 42.70 & 47.82 & 58.90 & 52.40 & 52.14 & 45.13 & 48.23 & 40.12 & 25.15 \\
\hline $\mathrm{Mn}$ & 75.81 & 71.22 & 68.14 & 70.84 & 73.71 & 58.42 & 67.33 & 68.52 & 57.72 & 51.33 & 23.10 \\
\hline $\mathrm{Ti}$ & 1.64 & 1.57 & 1.44 & 1.23 & 1.54 & 1.48 & 1.50 & 1.49 & 1.22 & 1.10 & 0.07 \\
\hline $\mathrm{Cr}$ & 10.13 & 10.01 & 9.92 & 9.02 & 8.09 & 8.99 & 9.51 & 8.54 & 7.74 & 7.41 & 6.93 \\
\hline $\mathrm{Cu}$ & 32.79 & 29.89 & 25.13 & 31.38 & 42.79 & 25.13 & 30.54 & 32.02 & 23.64 & 21.74 & $<15$ \\
\hline $\mathrm{Ni}$ & 62.63 & 65.55 & 60.88 & 58.7 & 61.41 & 62.67 & 56.46 & 53.30 & 47.83 & 47.18 & 41.93 \\
\hline $\mathrm{Zr}$ & 1.85 & 1.23 & 0.62 & 0.85 & 1.14 & 0.91 & 0.41 & 0.23 & 0.31 & 0.35 & 0.09 \\
\hline
\end{tabular}

1 - Adebayo road, 2 - Oke Iyinmi road, 3 - Ajilosun road, 4 - Mathew road, 5 - University road, 6 - Odo-Ado road, 7 - Ilawe road , 8 - Basiri road , 9 - State secretariat road , 10 - New Iyin road.

Total Fe concentrations in metal silt sediment ranged from $410.13 \mathrm{mg} / \mathrm{kg}$ at New Iyin road to $476.88 \mathrm{mg} / \mathrm{kg}$ at Adebayo road. Total Ti ranged from $1.101 \mathrm{mg} / \mathrm{kg}$ at New Iyin road to $1.728 \mathrm{mg} / \mathrm{kg}$ at Mathew road, ranged from $21.74 \mathrm{mg} / \mathrm{kg}$ to $42.79 \mathrm{mg} / \mathrm{kg}$ at New Iyin road and University road. Respectively ranged from $0.23 \mathrm{mg} / \mathrm{kg}$ to $1.85 \mathrm{mg} / \mathrm{kg}$ at Basiri roads and Adebayo road respectively. Ni ranged from $47.118 \mathrm{mg} / \mathrm{kg}$ at New Iyin road to $65.55 \mathrm{mg} / \mathrm{kg}$ at Oke Iyinmi road. Mn ranged from $51.33 \mathrm{mg} / \mathrm{kg}$ to $75.81 \mathrm{mg} / \mathrm{kg}$ at New Iyin road and Adebayo road as show in Table 2. The value of the metal at the road was higher than the control.

The three road, Adebayo Oke Iyinmi, and University road ranked highest in traffic density had the highest $\mathrm{Ti}, \mathrm{Cr}, \mathrm{Ni}, \mathrm{Zr}$ and $\mathrm{Mn}$ Contents in soil, which were above the recommended mean for agriculture soil but lower than the maximum tolerable level proposed for agriculture soil $(90-300 \mathrm{mg} / \mathrm{kg}),[13]$.

The mean and medium were used as estimates of central tendency standard error of the mean were all small. The distribution of original data for $\mathrm{Fe}, \mathrm{K}, \mathrm{Mn}, \mathrm{Ti}, \mathrm{Cr}, \mathrm{Cu}, \mathrm{Ni}$ and $\mathrm{Zr}$ are positive skewed. The substantial different in the symmetric parameter in the case of $\mathrm{K}, \mathrm{Ni}$, $\mathrm{Cu}, \mathrm{Fe}, \mathrm{Mn}$ and $\mathrm{Ti}$ indicate a non- normal distribution. This supporting a possibility of random infiltration of the metals from some anthropogenic source s. Large standard deviations in the case of $\mathrm{Fe}, \mathrm{Mn}, \mathrm{Cu}$ and $\mathrm{N}$ levels revealed their random fluctuating concentration level in the sediment. Among significant variable that controls or influences the distribution and concentration of heavy metal in the environment are the size of sediments and organic matter, Table 3 [14-16]. 
Table 3. Basic statistical parameters for the distribution of selected metals $\mathrm{mg} / \mathrm{kg}$ in road metal silt sediment samples from Ado-Ekiti.

\begin{tabular}{|c|c|c|c|c|c|c|}
\hline Element & Min & Max & Mean & Median & SD & SE \\
\hline $\mathrm{Fe}$ & 410.13 & 476.88 & 441.02 & 437.18 & 43.21 & 0.964 \\
\hline $\mathrm{K}$ & 40.12 & 58.90 & 50.14 & 49.98 & 29.40 & 0.588 \\
\hline $\mathrm{Mn}$ & 51.33 & 75.81 & 66.30 & 68.33 & 43.83 & 0.877 \\
\hline $\mathrm{Ti}$ & 1.101 & 1.617 & 1.43 & 1.468 & 0.62 & 0.012 \\
\hline $\mathrm{Cr}$ & 7.41 & 10.12 & 8.61 & 8.96 & 10.20 & 0.204 \\
\hline $\mathrm{Cu}$ & 21.74 & 42.79 & 29.51 & 30.22 & 24.14 & 0.483 \\
\hline $\mathrm{Ni}$ & 41.18 & 65.55 & 57.66 & 59.79 & 31.46 & 0.629 \\
\hline $\mathrm{Zr}$ & 0.31 & 1.85 & 0.79 & 0.77 & 0.48 & 0.009 \\
\hline
\end{tabular}

The degree of correlation between trace metal and organic matter and size distribution is often used to study the origin of many metals [17-27]. To verify this relationship in this study, correlations between all the metals and the parameter mention were carried out

\section{CONCLUSION}

XRF technique has been employed in order to establish the type of metal in soil sediment in Ado-Ekiti road. The experimental result indicate that the concentrations of heavy element varies from zone depend on the level of traffic volume on the road and population and they are greater than the level detected in the control soil. Anthropogenic release give rise to higher concentration of the metal relative to the normal background value and in some location their level exceed then alert level admitted by the Nigerian guideline.

\section{References}

[1] Stone M., Marsalek J., Air and Soil Pollution 87 (1996) 149-169.

[2] Pereira E., J. A. Baptista-Neto, B. J. Smith, J. J. Mcallister, Ann. Braz. Acad. Sci. 79 (2007) 739-750.

[3] Sutherland R. A., C. A. Tolosa, Environ. Pollut. 110 (2000) 483-495.

[4] Pagotto C., N. Remy, M. Legret, P. Le Cloirec, Environ. Technol. 22 (2001) 307-319..

[5] Ferguson J. E., N. D. Kim, Sci. Total Environ. 100 (1991) 125-150.

[6] Watts S. E. J., B. J. Smith, Sci. Total Environ. 146 (1994) 507-514.

[7] McAllister J. J., B. J. Smith, J. A. Baptista Neto, Environ. Geochem. Health 22 (2000) 195-210. 
[8] McAllister J. J., B. J. Smith J. A. Baptista Neto, J. K. Simpson, Environ. Geochem. Health 27 (2009) 429-441.

[9] McAllister J. J., B. J. Smith, J. A. Baptista Neto, J. K. Simpson, Environ. Geochem. Health 27 (2005) 429-441.

[10] Pereira E., J. A. Baptista-Neto, B. J. Smith, J. J. Mcallister, Ann. Braz. Acad. Sci. 79 (2007) 739-750.

[11] Sutherland R. A., Environ. Pollut. 121 (2003) 229-237.

[12] Awofolu O. R., Environ. Monitor. Assess. 105 (2005) 431-447.

[13] ICRCL. (1987). Interdepartmental committee for the Redevelopment of Contaminated Land, Guidance on the Assessment and Redevelopment of Contaminated Land. Paper $59 / 832^{\text {nd }}$ Edn. Department of the Environment, London

[14] Lin Y. P., T. P. Teng, T. K. Chang, Landscape Urban Plann. 62 (2002) 19-35.

[15] Huang K. M., S. Lin, Chemosphere 53 (2003) 1113-1121.

[16] Lakhan V. C., K. Cabana, P. D. LaValle, J. Coast. Res. 19 (2003) 600-608.

[17] Jumbe A. S., N. Nandini, Am. J. Environ. Sci. 5 (2009) 678-687.

[18] Ebad Bashiri, Jahanbakhsh Bashiri, Farhad Karimi, International Letters of Natural Sciences 3 (2013) 7-20.

[19] Daniszewski P., International Letters of Chemistry, Physics and Astronomy 3 (2012) 86-92.

[20] Daniszewski P., International Letters of Chemistry, Physics and Astronomy 4 (2012) 112-118.

[21] Daniszewski P., International Letters of Chemistry, Physics and Astronomy 5 (2012) 80-87.

[21] Daniszewski P., Konieczny R., International Letters of Chemistry, Physics and Astronomy 4 (2013) 91-97.

[22] Daniszewski P., Konieczny R., International Letters of Chemistry, Physics and Astronomy 8(3) (2013) 269-278.

[23] Daniszewski P., Konieczny R., International Letters of Chemistry, Physics and Astronomy 8(3) (2013) 279-287.

[24] Singare P. U., Talpade M. S., Dagli D. S., Bhawe V. G., International Letters of Chemistry, Physics and Astronomy 8(2) (2013) 94-104.

[25] Piotr Daniszewski, International Letters of Chemistry, Physics and Astronomy 10(2) (2013) 218-226

[26] Piotr Daniszewski, International Letters of Chemistry, Physics and Astronomy 12 (2013) $72-81$

[27] Piotr Daniszewski, International Letters of Chemistry, Physics and Astronomy 13 (2013) 13-22 